\title{
INDIRECT MINE AIR-COOLING BY COOLER OF WATER
}

\section{Introduction}

Air coolers for water are installations often used in mine air-conditioning systems. This cooler is equipped with a fan and a channel-shaped membrane heat exchanger, through which cooled air is forced by the fan. Water then flows through a system of copper pipes, picking up a heat from cooled fresh air. Water circulates in a closed cycle between the air cooler and the refrigerator evaporator, which is a part of the water cooler system (Cold water cycle). This is shown schematically in Figure 1, where the directions of flow of water, air and refrigerant are indicated - which are only examples as in real situations results can be different.

The condenser, which is invisible in Figure 1, is either cooled via water from a firefighting pipeline or heat is discharged from circulating water in a closed circuit between the condenser and evaporative cooler of water, where heat is passed over to the used air (which is a warm water cycle). Due to the fact that in this system a heat is transported to an evaporator via water, this form of air cooling is known as indirect cooling, as opposed to direct air cooling in an evaporator. An air cooler of water can be situated a great distance from the refrigerator - several hundred or even several thousand meters. Water temperature changes at this distance can be substantial therefore it is necessary to insulate all pipework.

Later in the article, mathematical equations and descriptions of indirect air cooling as well as a system using an evaporator for the cooling of water are shown. Both heat exchangers are the concentrated spatial elements, which allow for any sudden changes in the parameters of flowing media.

\footnotetext{
* AGH University of Science and Technology, Krakow; bernak@agh.edu.pl; filek@agh.edu.pl
} 


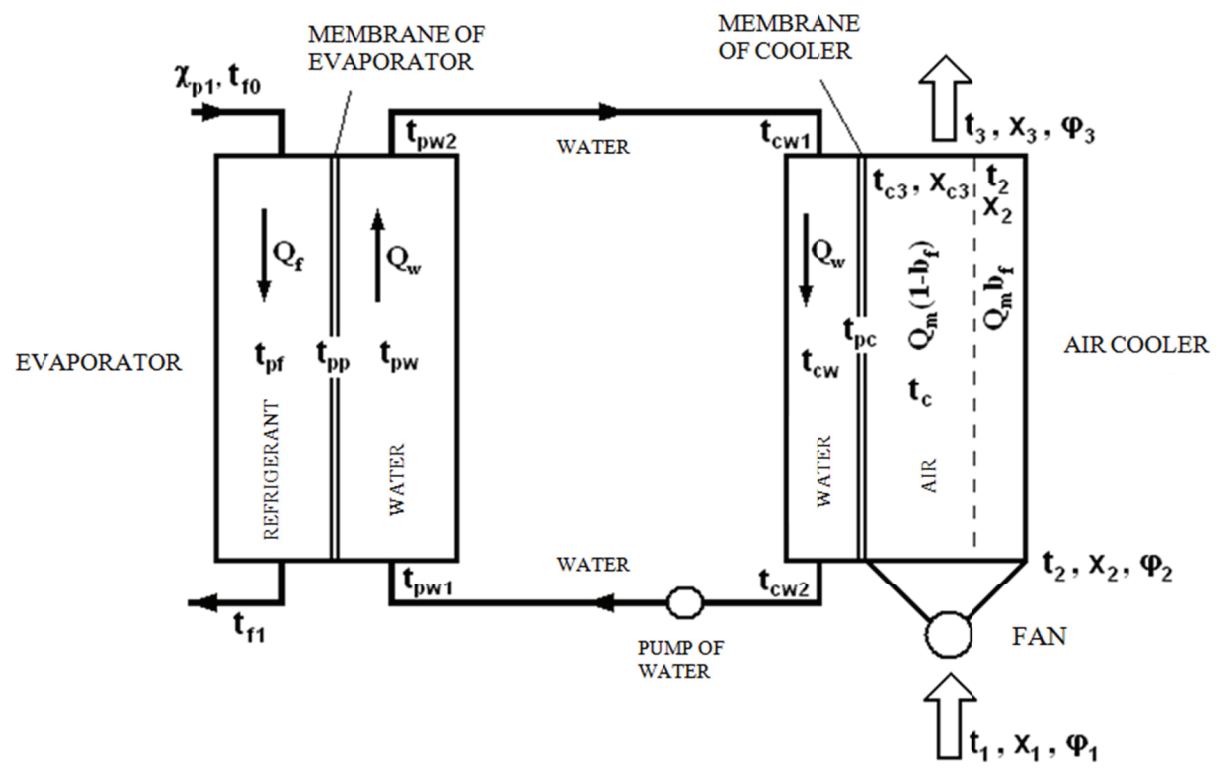

Fig. 1. Scheme of the flow of cooled air, cooled water and refrigerant through cooler and evaporator of refrigerator

\section{Mathematical description of work of indirect air cooling system}

The equations below look at the time allowed before either the air cooled water system, or the refrigerated cooler system are introduced. The following assumptions are accepted, which are known from previous elaborations, e.g. [1, 2]:

- heat losses to the surroundings in both exchangers are negligibly small (this assumption corresponds to the fact, that the heat exchange in cooler is between air and water and in evaporator - between water and refrigerant),

- thermal resistance of heat exchanger membranes is negligibly small,

- fan blowing air to the cooler of water raises the temperature without changing its specific humidity,

- a constant pressure of refrigerant, which is equal to evaporating pressure $p_{0}$, is in the evaporator,

- refrigerant flows to the evaporator as a wet saturated vapour (its partial evaporation is in expansion valve situated before evaporator) with temperature $t_{f 0}$, equal to evaporating temperature of refrigerant under pressure $p_{0}$.

\subsection{Cooler of water}

Cooling air flows to the fan of the cooler with temperature $t_{1}$, specific humidity $x_{1}$ and relative humidity $\varphi_{1}$, to the exchanger it flows with parameters $t_{2}, x_{2}$ and $\varphi_{2}$, and comes out with parameters $t_{3}, x_{3}$ and $\varphi_{3}$. 
Taken into account these assumptions, it can be written:

$$
t_{2}=t_{1}+\Delta t_{\text {wen }} ; \quad x_{2}=x_{1}
$$

where $\Delta t_{\text {wen }}-$ temperature increase of air in the fan $\left[{ }^{\circ} \mathrm{C}\right]$.

Cold water at a temperature $t_{c w 1}$ flows to the exchanger (usually counter-current flow), then it is heated to $\Delta t_{c w}$ and leaves the exchanger charged with temperature $t_{c w 2}$. It can be written:

$$
t_{c w 2}=t_{c w 1}+\Delta t_{c w}
$$

When, condensation of water vapour from air does not occur, which is when the temperature of outer surface of exchanger membrane (copper pipes with cold water) is higher than or equal to the temperature of dew point of air, dry cooling is set - temperature of air decreases and its specific humidity is constant:

$$
\begin{aligned}
& t_{3}<t_{2} \\
& x_{3}=x_{2}
\end{aligned}
$$

Otherwise, water from air is condensing on the pipes and temperature of air and its specific humidity are lower:

$$
\begin{aligned}
& t_{3}<t_{2} \\
& x_{3}<x_{2}
\end{aligned}
$$

\section{Result of cooling air enthalpy in exchanger of cooler of water - dry cooling}

In steady state the enthalpy of air flowing to cooler exchanger in time $\Delta \tau$ is equal $[3,4,5]$ :

$$
H_{s 2}=Q_{m}\left[\left(c_{p}+c_{w} x_{2}\right) t_{2}+r_{p} x_{2}\right] \Delta \tau
$$

The enthalpy of air flowing from exchanger in the same time:

$$
H_{s 3}=Q_{m}\left[\left(c_{p}+c_{w} x_{2}\right)\left[\left(1-b_{f}\right) t_{c 3}+b_{f} t_{2}\right]+r_{p} x_{2}\right] \Delta \tau
$$

where:

$b_{f}$ - cooler by-pass coefficient, understood as $[6,7]$ a ratio of cooled mass (conventional) to the whole mass [-],

$c_{p}$ - specific heat of dry air at constant pressure $[\mathrm{J} /(\mathrm{kg} \cdot \mathrm{K})]$,

$c_{w}-$ specific heat of water vapour at constant pressure $[\mathrm{J} /(\mathrm{kg} \cdot \mathrm{K})]$,

$Q_{m}$ - mass flow rate of dry air in the cooler $[\mathrm{kg} / \mathrm{s}]$,

$r_{p}$ - latent heat of water evaporation $/$ condensation $[\mathrm{J} / \mathrm{kg}]$

$t_{c 3}$ - temperature of cooled part of air at the outlet of exchanger $\left[{ }^{\circ} \mathrm{C}\right]$ (in the method of by-pass coefficient is assumed that in the heat and mass exchange participates only this part of air, at mass equal $Q_{m}\left(1-b_{f}\right) \Delta \tau$, while the rest part at mass $Q_{m} b \Delta \tau$ flows by the exchanger without temperature and humidity change; state of air leaving the exchanger is a result of these two streams mixtures). 
To the exchanger membrane the enthalpy $\Delta \tau$ is passed from air in time:

where:

$$
H_{c p}=\alpha_{c z} F_{c z}\left(t_{c}-t_{p c}\right) \Delta \tau
$$

$\alpha_{c z}-$ heat transfer coefficient on the outer surface of exchanger membrane $\left[\mathrm{W} /\left(\mathrm{m}^{2} \cdot \mathrm{K}\right)\right]$,

$F_{c z}-$ a field of outer surface heat transfer in the exchanger $\left[\mathrm{m}^{2}\right]$,

$t_{c}$ - average temperature of the cooled part of air in the exchanger $\left[{ }^{\circ} \mathrm{C}\right]$,

$t_{p c}-$ average temperature of exchanger membrane $\left[{ }^{\circ} \mathrm{C}\right]$.

Result of the air enthalpy in the exchanger at steady dry cooling takes a form:

$$
H_{s 3}-H_{s 2}+H_{c p}=0
$$

After substituting formulas (5)-(7) into the formula (8) the equation is received:

$$
t_{2}-t_{c 3}=\frac{\alpha_{c z} F_{c z}}{Q_{m}\left(1-b_{f}\right)\left(c_{p}+c_{w} x_{2}\right)}\left(t_{c}-t_{p c}\right)
$$

\section{Result of cooling air enthalpy in exchanger of cooler of water - wet cooling}

The enthalpy $H_{m 2}$ of air flows to the exchanger in time $\Delta \tau$ is expressed in this case, as previously, by the formula:

$$
H_{m 2}=H_{s 2}=Q_{m}\left[\left(c_{p}+c_{w} x_{2}\right) t_{2}+r_{p} x_{2}\right] \Delta \tau
$$

While the enthalpy $H_{m 3}$ of air flows from the exchanger in time $\Delta \tau$ is equal:

$$
H_{m 3}=Q_{m}\left[\left(1-b_{f}\right)\left(c_{p} t_{c 3}+c_{w} t_{c 3} x_{c 3}+r_{p} x_{c 3}\right)+b_{f}\left(c_{p} t_{2}+c_{w} t_{2} x_{2}+r_{p} x_{2}\right)\right] \Delta \tau
$$

where $x_{c 3}$-specific humidity of cooled part of air at the outlet of exchanger $[\mathrm{kg} / \mathrm{kg}]$.

The enthalpy $H_{c p}$ given the membrane is expressed by the formula (7). The enthalpy of condensed water $H_{w w}$ should be included; it was assumed here, that the temperature of condensed water is equal to the temperature of cooled part of air at the outlet of the exchanger:

$$
H_{w w}=Q_{m}\left(1-b_{f}\right) c_{c} t_{c 3}\left(x_{2}-x_{c 3}\right) \Delta \tau
$$

where $c_{c}$ - specific heat of water $[\mathrm{J} /(\mathrm{kg} \cdot \mathrm{K})]$.

Result of the air enthalpy at wet cooling is expressed as follow:

$$
H_{m 3}-H_{m 2}+H_{c p}+H_{w w}=0
$$

After substituting formulas (7) and (10)-(12) into the formula (13) the equation is received

$$
c_{p}\left(t_{2}-t_{c 3}\right)+c_{w}\left(t_{2} x_{2}-t_{c 3} x_{c 3}\right)+\left(r_{p}-c_{c} t_{c 3}\right)\left(x_{2}-x_{c 3}\right)=\frac{\alpha_{c z} F_{c z}}{Q_{m}\left(1-b_{f}\right)}\left(t_{c}-t_{p c}\right)
$$

Is easy to observed that equation (14) is in the form (9) at dry cooling (i.e. when $x_{c 3}=x_{2}$ ). 


\section{Result of membrane enthalpy in exchanger of water cooler}

Enthalpy received from air in time $\Delta \tau$ is equal (formula (7)), and enthalpy transferred to cooling water is:

where:

$$
H_{c w}=\alpha_{c w} F_{c w}\left(t_{p c}-t_{c w}\right) \Delta \tau
$$

$\alpha_{c w}-$ heat transfer coefficient on the inner surface of exchanger membrane $\left[\mathrm{W} /\left(\mathrm{m}^{2} \cdot \mathrm{K}\right)\right]$,

$F_{c w}-$ a field of inner surface heat transfer in the exchanger $\left[\mathrm{m}^{2}\right]$,

$t_{c w}-$ average temperature of cooling water in the cooler $\left[{ }^{\circ} \mathrm{C}\right]$.

In steady state, result of membrane enthalpy has the form:

$$
H_{c p}=H_{c w}
$$

and after substituting it gives:

$$
\alpha_{c z} F_{c z}\left(t_{c}-t_{p c}\right)=\alpha_{c w} F_{c w}\left(t_{p c}-t_{c w}\right)
$$

\section{Result of water enthalpy in exchanger of water cooler}

Enthalpy of cold water flows to the exchanger in time $\Delta \tau$ is:

$$
H_{c w 1}=Q_{w} c_{c} t_{c w 1} \Delta \tau
$$

and enthalpy of water flows from the exchanger in this time:

$$
H_{c w 2}=Q_{w} c_{c} t_{c w 2} \Delta \tau
$$

where:

$Q_{w}-$ mass flow rate of cold water (in the cooler of air and evaporator) [kg/s],

$t_{c w 1}-$ temperature of water at the inlet of the exchanger $\left[{ }^{\circ} \mathrm{C}\right]$,

$t_{c w 2}-$ temperature of water at the outlet of the exchanger $\left[{ }^{\circ} \mathrm{C}\right]$.

From the membrane of exchanger to water the enthalpy $H_{c w}$ is transferred in time $\Delta \tau$ (formula (15)).

Result of water enthalpy in the exchanger of cooler of water has a form:

$$
H_{c w 2}-H_{c w 1}-H_{c w}=0
$$

After substituting formulas (15) and (18)-(20) the equation is received:

$$
t_{p c}-t_{c w}=\frac{Q_{w} c_{c}\left(t_{c w 2}-t_{c w 1}\right)}{\alpha_{c w} F_{c w}}
$$

Equations (9) or (14), (17) and (21) create a system of equations, which describes the work of air cooler of water in steady state.

\subsection{Evaporator}

The evaporator is a component of the water cooler similar to a cooler of water. It consists of a membrane exchanger - with piped refrigerant, with external chilled water. Refrigerant 
flows under the influence of a working compressor, evaporates and receives the heat from water via the membrane, which is a wall of pipes.

The refrigerant circulates in a closed circuit to and from the evaporator in form of liquid and vapour mixture at temperature $t_{f 0}$ and vapour quality $\chi_{p 1}$, it arises its temperature at $\Delta t_{f \mathrm{p}}$ and leaves the evaporator in the form of superheated steam temperature $t_{f 1}$ and vapour quality $\chi_{p 2}$ (vapour quality - mass of gaseous phase of wet steam to its total mass). While water flows to the evaporator at a temperature $t_{p w 1}$, is cooled in it at $\Delta t_{p w}$ and flow out with temperature $t_{p w 2}$. It can be written:

$$
\begin{gathered}
t_{f 1}=t_{f 0}+\Delta t_{f p} ; \quad \chi_{p 1}=1 \\
t_{p w 2}=t_{p w 1}-\Delta t_{p w}
\end{gathered}
$$

\section{Result of cold water enthalpy in evaporator}

Enthalpy of water flows to the evaporator in time $\Delta \tau$ is:

$$
H_{p w 1}=Q_{w} c_{c} t_{p w 1} \Delta \tau
$$

and enthalpy of water flows from evaporator in this time:

$$
H_{p w 2}=Q_{w} c_{c} t_{p w 2} \Delta \tau
$$

Enthalpy $H_{p w}$ is transferred to the membrane of evaporator from water in time $\Delta \tau$ :

$$
H_{p w}=\alpha_{p z} F_{p z}\left(t_{p w}-t_{p p}\right) \Delta \tau
$$

Result of water enthalpy in evaporator has form:

$$
H_{p w 1}-H_{p w 2}-H_{p w}=0
$$

After substituting formulas (24)-(27) the equation is received:

$$
t_{p w}-t_{p p}=\frac{Q_{w} c_{c}\left(t_{p w 1}-t_{p w 2}\right)}{\alpha_{p z} F_{p z}}
$$

where:

$t_{p w}-$ average temperature of water in evaporator $\left[{ }^{\circ} \mathrm{C}\right]$,

$t_{p p}-$ average temperature of membrane in evaporator $\left[{ }^{\circ} \mathrm{C}\right]$,

$\alpha_{p z}-$ heat transfer coefficient on the outer surface of evaporator membrane $\left[\mathrm{W} /\left(\mathrm{m}^{2} \cdot \mathrm{K}\right)\right]$,

$F_{p z}-$ a field of outer surface heat transfer in evaporator $\left[\mathrm{m}^{2}\right]$.

\section{Result of enthalpy of evaporator membrane}

Enthalpy received from water in time $\Delta \tau$ is equal $H_{p w}$ (formula (26)), and enthalpy transferred to refrigerant is:

$$
H_{p f}=\alpha_{p w} F_{p w}\left(t_{p p}-t_{p f}\right) \Delta \tau
$$


where:

$\alpha_{p w}-$ heat transfer coefficient on the inner surface of evaporator membrane $\left[\mathrm{W} /\left(\mathrm{m}^{2} \cdot \mathrm{K}\right)\right]$,

$F_{p w}-$ a field of inner surface heat transfer in evaporator $\left[\mathrm{m}^{2}\right]$,

$t_{p f}-$ average temperature of refrigerant in evaporator $\left[{ }^{\circ} \mathrm{C}\right]$; it is generally considered [e.g. 7, 8] that $t_{p f}=t_{f 0}$.

In a steady state enthalpy of evaporator membrane has a form:

$$
H_{p w}=H_{p f}
$$

after substituting it gives:

$$
\alpha_{p z} F_{p z}\left(t_{p w}-t_{p p}\right)=\alpha_{p w} F_{p w}\left(t_{p p}-t_{p f}\right)
$$

\section{Result of refrigerant enthalpy in evaporator}

In the evaporator a pressure $p_{0}$ is obtained inside the refrigerant pipes. As mentioned, a wet vapour of refrigerant with a temperature equal to the evaporating temperature at pressure $\left(t_{f 0}\right)$ and degree of dryness $0<\chi_{p 1}<1$ flows to the evaporator and dry superheated steam with parameters $t_{f 1}>t_{f 0}$ and $\chi_{p 2}=1$ flows from the evaporator.

Refrigerant enthalpy flowing to the evaporator in time $\Delta \tau$ is:

$$
H_{p f 1}=Q_{f}\left[c_{c f 0} t_{f 0}\left(1-\chi_{p 1}\right)+\left(c_{c f 0} t_{f 0}+r_{p f 0}\right) \chi_{p 1}\right] \Delta \tau
$$

and refrigerant enthalpy flowing from the evaporator in this time is:

$$
H_{p f 2}=Q_{f}\left[c_{p f 0}\left(t_{f 1}-t_{f 0}\right)+c_{c f 0} t_{f 0}+r_{p f 0}\right] \Delta \tau
$$

where:

$Q_{f}$ - mass flow rate of refrigerant $[\mathrm{kg} / \mathrm{s}]$,

$c_{c f 0}-$ specific heat of refrigerant in evaporator $[\mathrm{J} /(\mathrm{kg} \cdot \mathrm{K})]$,

$c_{p f 0}$ - specific heat of refrigerant in evaporator at constant pressure $[\mathrm{J} /(\mathrm{kg} \cdot \mathrm{K})]$,

$r_{p f 0}-$ heat of evaporation of refrigerant in evaporator $[\mathrm{J} / \mathrm{kg}]$,

$\chi_{p 1}-$ degree of dryness of refrigerant at the inlet to evaporator [-].

From evaporator membrane to refrigerant the enthalpy $H_{p f}$ is transferred in time $\Delta \tau$ (formula (29)).

Result of refrigerant enthalpy in evaporator:

$$
H_{p f 2}-H_{p f 1}-H_{p f}=0
$$

After substituting formulas (29), (32) and (33) to (34) the equation is received:

$$
t_{p p}-t_{f p}=\frac{Q_{f}}{\alpha_{p w} F_{p w}}\left[c_{p f 0}\left(t_{f 1}-t_{f 0}\right)+r_{p f 0}\left(1-\chi_{p 1}\right)\right]
$$

Equations (28), (31) and (35) create the set of equations describing the work of evaporator in steady state. 
From the evaporator, refrigerant vapour flows to the refrigerator (directly or through inner heat exchanger), to the condenser, then an expansion valve (directly or through inner heat exchanger) and back to the evaporator. These elements of the refrigerator, excluding the evaporator, are not a subject of consideration in this article.

Excluding temperature of membrane of cooler of water and evaporator from equations can be obtained:

- for air cooler of water (equations (36) and (37) occur alternatively):

$$
\begin{gathered}
k_{c} F_{c}\left(t_{c}-t_{c w}\right)=Q_{m}\left(1-b_{f}\right)\left(c_{p}+c_{w} x_{2}\right)\left(t_{2}-t_{c 3}\right) \\
k_{c} F_{c}\left(t_{c}-t_{c w}\right)=Q_{m}\left(1-b_{f}\right)\left[c_{p}\left(t_{2}-t_{c 3}\right)+c_{w}\left(t_{2} x_{2}-t_{c 3} x_{c 3}\right)+\left(r_{p}-c_{c} t_{c 3}\right)\left(x_{2}-x_{c 3}\right)\right] \\
k_{c} F_{c}\left(t_{c}-t_{c w}\right)=Q_{w} c_{c}\left(t_{c w 2}-t_{c w 1}\right)
\end{gathered}
$$

- for evaporator:

$$
\begin{gathered}
k_{p} F_{p}\left(t_{p w}-t_{p f}\right)=Q_{w} c_{c}\left(t_{p w 1}-t_{p w 2}\right) \\
k_{p} F_{p}\left(t_{p w}-t_{p f}\right)=Q_{f}\left[c_{p f 0}\left(t_{f 1}-t_{f 0}\right)+r_{p f 0}\left(1-\chi_{p 1}\right)\right]
\end{gathered}
$$

where:

$$
\begin{gathered}
k_{c} F_{c}=\frac{\alpha_{c w} F_{c w} \alpha_{c z} F_{c z}}{\alpha_{c w} F_{c w}+\alpha_{c z} F_{c z}} \\
k_{p} F_{p}=\frac{\alpha_{p w} F_{p w} \alpha_{p z} F_{p z}}{\alpha_{p w} F_{p w}+\alpha_{p z} F_{p z}}
\end{gathered}
$$

Substituting the log mean temperature differences (LMTD) of media in heat exchangers to the above equations [8]:

$$
\begin{gathered}
t_{c}-t_{c w}=\frac{\left(t_{2}-t_{c w 2}\right)-\left(t_{c 3}-t_{c w 1}\right)}{\ln \frac{t_{2}-t_{c w 2}}{t_{c 3}-t_{c w 1}}} \\
t_{p w}-t_{p f}=\frac{t_{p w 1}-t_{p w 2}}{\ln \frac{t_{p w 1}-t_{f 0}}{t_{p w 2}-t_{f 0}}}
\end{gathered}
$$

can be obtained:

$$
\begin{gathered}
\ln \frac{t_{2}-t_{c w 2}}{t_{c 3}-t_{c w 1}}=\frac{k_{c} F_{c}\left[\left(t_{2}-t_{c w 2}\right)-\left(t_{c 3}-t_{c w 1}\right)\right]}{Q_{m}\left(1-b_{f}\right)\left(c_{p}+c_{w} x_{2}\right)\left(t_{2}-t_{c 3}\right)} \\
\ln \frac{t_{2}-t_{c w 2}}{t_{c 3}-t_{c w 1}}=\frac{k_{c} F_{c}\left[\left(t_{2}-t_{c w 2}\right)-\left(t_{c 3}-t_{c w 1}\right)\right]}{Q_{m}\left(1-b_{f}\right)\left[c_{p}\left(t_{2}-t_{c 3}\right)+c_{w}\left(t_{2} x_{2}-t_{c 3} x_{c 3}\right)+\left(r_{p}-c_{c} t_{c 3}\right)\left(x_{2}-x_{c 3}\right)\right]}
\end{gathered}
$$




$$
\begin{aligned}
\ln \frac{t_{2}-t_{c w 2}}{t_{c 3}-t_{c w 1}} & =\frac{k_{c} F_{c}\left[\left(t_{2}-t_{c w 2}\right)-\left(t_{c 3}-t_{c w 1}\right)\right]}{Q_{w} c_{c}\left(t_{c w 2}-t_{c w 1}\right)} \\
& \ln \frac{t_{p w 1}-t_{f 0}}{t_{p w 2}-t_{f 0}}=\frac{k_{p} F_{p}}{Q_{w} c_{c}} \\
\ln \frac{t_{p w 1}-t_{f 0}}{t_{p w 2}-t_{f 0}}= & \frac{k_{p} F_{p}\left(t_{p w 1}-t_{p w 2}\right)}{Q_{f}\left[c_{p f 0}\left(t_{f 1}-t_{f 0}\right)+r_{p f 0}\left(1-\chi_{p 1}\right)\right]}
\end{aligned}
$$

The system of equations (45)-(49) is a mathematical model of the steady air cooling by a cooler of water with the evaporator of refrigerator constituting a water cooler. In the equations of air cooling (45)-(47) parameters of part of the air-cooled $\left(t_{c 3}\right.$ and $\left.x_{c 3}\right)$ occurs rather than parameters of whole stream at the outlet of cooler $\left(t_{3}\right.$ and $\left.x_{3}\right)$. These last parameters can be determined from the system of equations:

$$
\left\{\begin{array}{l}
t_{3}=\frac{\left(c_{p} t_{c 3}+c_{w} t_{c 3} x_{c 3}+r_{p} x_{c 3}\right)\left(1-b_{f}\right)+\left(c_{p} t_{2}+c_{w} t_{2} x_{2}+r_{p} x_{2}\right) b_{f}-r_{p} x_{3}}{c_{p}+c_{w} x_{3}} \\
x_{3}=\left\{\begin{array}{lll}
x_{c 3}\left(1-b_{f}\right)+x_{12} b_{f} & \text { where } & x_{c 3}\left(1-b_{f}\right)+x_{2} b_{f} \leq x_{n}\left(t_{3}\right) \\
x_{n}\left(t_{3}\right) & \text { where } & x_{c 3}\left(1-b_{f}\right)+x_{2} b_{f}>x_{n}\left(t_{3}\right)
\end{array}\right.
\end{array}\right.
$$

In the system (50) $x_{n}\left(t_{3}\right)$ and $x_{c 3}$ (equal $\left.x_{n}\left(t_{c 3}\right)\right)$ relationship [9] can be expressed:

$$
\begin{aligned}
& x_{n}\left(t_{3}\right)=\frac{379.8 \cdot 10^{u}}{b-610.6 \cdot 10^{u}} \quad \text { where } \quad u=\frac{7.5 t_{3}}{t_{3}+237.29} \\
& x_{c 3}=\frac{379.8 \cdot 10^{w}}{b-610.6 \cdot 10^{w}} \quad \text { where } \quad w=\frac{7.5 t_{c 3}}{t_{c 3}+237.29}
\end{aligned}
$$

where:

$b-$ absolute pressure of air $[\mathrm{Pa}]$,

$x_{n}(t)-$ specific humidity of air in state of saturation in temperature $t[\mathrm{~kg} / \mathrm{kg}]$.

\section{A numerical example}

Temperature, specific humidity and relative humidity of the air at the outlet of cooler of water supplied by cold water from evaporator of the refrigerator with refrigerant R507 should be determined.

This example was solved by using a computer program based on a system of equations (46)-(50), where the unknowns are the water temperatures at the inlet and outlet of exchangers and outlet parameters of air. Numerical data concerning cooler of water are as follows:

- bypass coefficient $b_{f}=0.1$,

- absolute pressure of air $b=103 \mathrm{kPa}$,

- volume flow of air $Q=10 \mathrm{~m}^{3} / \mathrm{s}$, 
- air temperature at the inlet of fan $t_{1}=30^{\circ} \mathrm{C}$,

- temperature increase of air in the fan $\Delta t_{\text {wen }}=2.5^{\circ} \mathrm{C}$,

- relative humidity of air at the inlet of fan $\varphi_{1}=80 \%$.

From the data above the following can be obtained:

- temperature at the inlet of exchanger (formula (1)) $t_{2}=32.5^{\circ} \mathrm{C}$ air,

- specific humidity of air at the inlet of fan (and at the inlet of cooler) $x_{1}=x_{2}=21.190 \mathrm{~g} / \mathrm{kg}$,

- relative humidity of air at the inlet of cooler $\varphi_{2}=69.41 \%$,

- mass flow rate of dry air from formula:

$$
Q_{m}=Q_{\rho}
$$

where $\rho$ is a density of dry airparameters of air at the inlet of exchanger were obtained by substituting $t=t_{2}$ and $x=x_{2}$ :

$$
\rho=\frac{b}{461,5(t+273,15)(x+0,622)}
$$

- mass flow rate of cold water $Q m=11.353 \mathrm{~kg} / \mathrm{s}, Q w=8 \mathrm{~kg} / \mathrm{s}$,

- temperature increase of water on the way from cooler to evaporator (non-insulated pipeline) $\Delta t_{w 1}=0.5^{\circ} \mathrm{C}$,

- field of inner surface of heat transfer $F_{c w}=60 \mathrm{~m} 2$,

- field of outer surface of heat transfer $F_{c z}=70 \mathrm{~m} 2$,

- heat transfer coefficient from the water side $\alpha_{c w}=5447.9 \mathrm{~W} /\left(\mathrm{m}^{2} \cdot \mathrm{K}\right)$,

- heat transfer coefficient from the air side $\alpha_{c z}=183.06 \mathrm{~W} /\left(\mathrm{m}^{2} \cdot \mathrm{K}\right)$ (these coefficient values were received from formulas given in $[2,7,10])$.

From above data it can be determined according to (41), $k_{c} F_{c}=12330.8 \mathrm{~W} / \mathrm{K}$, for evaporator:

- degree of dryness of wet vapour of refrigerant at the inlet to evaporator $\chi_{p 1}=0.35[-]$,

- temperature increase of water on the way from evaporator to cooler (insulated pipeline) $\Delta t_{w 2}=0.1^{\circ} \mathrm{C}$,

- inner field of heat transfer $F_{p w}=90 \mathrm{~m}^{2}$,

- outer field of heat transfer $F_{p z}^{p w}=100 \mathrm{~m}^{2}$,

- heat transfer coefficient from the refrigerant side $\alpha_{p w}=757 \mathrm{~W} /\left(\mathrm{m}^{2} \cdot \mathrm{K}\right)$,

- heat transfer coefficient from the water side $\alpha_{p z}=2000 \mathrm{~W} /\left(\mathrm{m}^{2} \cdot \mathrm{K}\right)$ (this value $\alpha_{p w}$ obtained according to $[2,6]$, value of coefficient $\alpha_{p z}$ was given arbitrarily).

From above data it can be determined according to (42), $k_{p} F_{p}=50818.6 \mathrm{~W} / \mathrm{K}$ :

- evaporation pressure of refrigerant $p_{0}=700 \mathrm{kPa}$,

- superheated vapour of refrigerant at the outlet of evaporator $\Delta \mathrm{t}_{\mathrm{f}}=10^{\circ} \mathrm{C}$, (from this value $\Delta_{t f}$ value of mass stream of refrigerant was received),

- mass stream of refrigerant $Q_{\mathrm{f}}=2.134 \mathrm{~kg} / \mathrm{s}$.

Evaporative temperature of refrigerant $t_{f 0}$, its relative humidity $c_{p f 0}$ and evaporation heat $r_{p f 0}$ can be obtained according to $[11,12]$. 
The results of these calculations are summarized in Table 1. Also presented in this Table are the thermal powers of: air cooler of water $N_{c}$ - from the air side $N_{c p}$ (with division into sensible capacity of air cooling $N_{c j}$ and latent capacity of dehumidification $N_{c u}$ ) and from water side $N_{c w}$ and from the evaporator side $N_{p}$ - from the water side $N_{p w}$ and from the refrigerant side $N_{p f}$. To their calculation the equation were used:

$$
\begin{aligned}
& N_{c j}=Q_{m}\left[c_{p}\left(t_{2}-t_{3}\right)+c_{w}\left(t_{2} x_{2}-t_{3} x_{3}\right)\right] \\
& N_{c u}=Q_{m}\left(r_{p}-c_{c} t_{3}\right)\left(x_{2}-x_{3}\right) \\
& N_{c p}=N_{c j}+N_{c u} \\
& N_{c w}=Q_{w} c_{c}\left(t_{c w 2}-t_{c w 1}\right) \\
& N_{p w}=Q_{w} c_{c}\left(t_{p w 1}-t_{p w 2}\right) \\
& N_{p f}=Q_{f}\left[c_{p f 0}\left(t_{f 1}-t_{f 0}\right)+r_{p f 0}\left(1-\chi_{p 1}\right)\right]
\end{aligned}
$$

\section{TABELE 1}

Indirect air cooling by cooler of water - the results of calculations

\begin{tabular}{|l|c|c|c|}
\hline \multicolumn{1}{|c|}{ Calculated value } & Symbol & Unit & Value \\
\hline Air temperature at the outlet of the cooler of water & $t_{3}$ & ${ }^{\circ} \mathrm{C}$ & 23.32 \\
\hline Specific humidity of air at the outlet of cooler of water & $x_{3}$ & $\mathrm{~g} / \mathrm{kg}$ & 17.14 \\
\hline Relative humidity of air at the outlet of cooler of water & $\varphi_{3}$ & $\%$ & 96.43 \\
\hline Temperature of water at the inlet of cooler of water & $t_{c w 1}$ & ${ }^{\circ} \mathrm{C}$ & 6.04 \\
\hline Temperature of water at the outlet of cooler of water & $t_{c w 2}$ & ${ }^{\circ} \mathrm{C}$ & 12.66 \\
\hline Temperature of water at the inlet of the evaporator & $t_{p w 1}$ & ${ }^{\circ} \mathrm{C}$ & 13.16 \\
\hline Temperature of water at the outlet of the evaporator & $t_{p w 2}$ & ${ }^{\circ} \mathrm{C}$ & 5.94 \\
\hline Evaporating temperature of refrigerant in the evaporator & $t_{f 0}$ & ${ }^{\circ} \mathrm{C}$ & 3.91 \\
\hline Sensible capacity of air cooler of water & $N_{c j}$ & $\mathrm{~kW}$ & 111.0 \\
\hline Latent capacity of air cooler of water & $N_{c u}$ & $\mathrm{~kW}$ & 110.7 \\
\hline Total capacity of air cooler of water counted from the air side & $N_{c p}$ & $\mathrm{~kW}$ & 221.7 \\
\hline Total capacity of air cooler of water counted from the water side & $N_{c w}$ & $\mathrm{~kW}$ & 221.7 \\
\hline Total capacity of evaporator counted from the water side & $N_{p w}$ & $\mathrm{~kW}$ & 241.9 \\
\hline Total capacity of evaporator counted from the refrigerant side & $N_{p f}$ & $\mathrm{~kW}$ & 241.9 \\
\hline
\end{tabular}

\section{REFERENCES}

[1] Nowak B., Filek K.: Mathematical description of media parameters in the compression refrigerator. Archives of Mining Sciences, vol. 54, iss. 1, 2009, pp. 13-34

[2] Nowak B., Filek K., Euska P.: A Verification of Mathematical Model of Mine Air Compression Refrigerator Cooperating with the Evaporative Water Cooler. Archives of Mining Sciences, vol. 55, iss. 3, 2010, pp. 441-467 
[3] Frycz A.: Klimatyzacja kopalń. Katowice, Wydawnictwo „Śląsk” 1981

[4] Jones W.P.: Klimatyzacja. Warszawa, Arkady 2001

[5] Pawiński J., Roszkowski J., Strzemiński J.: Przewietrzanie kopalń. Katowice, Śląskie Wydawnictwo Techniczne 1995

[6] Häussler W.: Zastosowanie wykresu i-x w inżynierii sanitarnej. Warszawa, Arkady 1971

[7] Kołodziejczyk L., Rubik M.: Technika chłodnicza w klimatyzacji. Warszawa, Arkady 1976

[8] Wacławik J., Cygankiewicz J., Knechtel J.: Warunki klimatyczne w kopalniach głębokich. Poradnik nr 4, Biblioteka Szkoły Eksploatacji Podziemnej, Kraków 1995

[9] Roszczynialski W., Trutwin W., Wacławik J.: Kopalniane pomiary wentylacyjne. Katowice, Wydawnictwo „Śląsk” 1992

[10] Hobler T.: Ruch ciepła i wymienniki. Wydanie IV. Warszawa, Wydawnictwa Naukowo-Techniczne 1971

[11] Bonca Z., Butrymowicz D., Dambek D., Depta A., Targański W.: Czynniki chłodnicze i nośniki ciepła. Własności cieplne, chemiczne i eksploatacyjne. Poradnik. Gdańsk, Wydawnictwo IPPU Miasta 1998

[12] Platzer B., Polt A., Maurer G.: Thermophysical Properties of Refrigerants. Berlin, Heidelberg, Springer-Verlag 1990 